\title{
Repetibilidade e número de colheita de características para seleção de clones de variedades viníferas
}

\author{
Repeatability and number of harvest characteristics \\ for selection of clones of grape varieties
}

\section{RESUMO}

O presente trabalho teve por objetivo obter estimativas dos coeficientes de repetibilidade ( $r$ ), determinação ou grau de previsibilidade $\left(R^{2}\right)$ de características de clones de variedades de uvas viniferas e determinar o número de medições necessárias capaz de proporcionar niveis de certeza (80, 90 e 95\%) da predição do valor real dos indivíduos para cada caráter. O trabalho foi realizado a partir de dados médios de oito características, provenientes de dois experimentos sobre o comportamento de clones de duas variedades viniferas, avaliados entre os anos de 1989 e 1992. Com base nas médias de cada colheita dos dois experimentos, obtiveram-se as estimativas do coeficiente de repetibilidade $(\hat{\rho}) e$ o coeficiente de determinação ou grau de previsibilidade $\left(R^{2}\right)$ de todas as características avaliadas. Na estimação do coeficiente de repetibilidade, foi utilizado o método da análise de variância. As estimativas dos coeficientes de repetibilidade obtidas para as duas variedades apresentam valores de magnitude muito semelhantes. As estimativas de repetibilidade, nas oito características, são superiores a 0,60, demonstrando regularidade do desempenho dos clones nas várias colheitas e confiabilidade na discriminação genotípica superior a $80 \%$. O emprego de três colheitas é adequado para que a seleção seja praticada com previsibilidade do valor real do genótipo acima de $80 \%$.
\end{abstract}

Adeliano Cargnin ${ }^{1}$
Palavras-chave: melhoramento, variabilidade, seleção clonal, Vitis vinifera.

\section{ABSTRACT}

This study aimed to estimate the coefficients of repeatability $(r)$, determination or degree of predictability $\left(R^{2}\right)$ of clones characteristics of wine grapes varities, and determine the number of measurements required, capable to provide levels of certainty (80, 90 and 95\%) of the real prediction l value of individuals for each character. The study was conducted from average data of eight characteristics from two experiments on the behavior of clones from two grape varieties, evaluated between the years 1989 and 1992. Based on the average of two experiments of each harvest, it was obtained estimates of the repeatability coefficient $(\hat{\rho})$ and the coefficient of determination or degree of predictability $\left(R^{2}\right)$ for all traits. In the estimation of the repeatability coefficient, the method of analysis of variance was used. Coefficient of repeatability obtained for the two varieties have values very similar magnitude. Repeatability estimates for the eight characteristics are superior to 0.60, demonstrating constancy of clones performance in several crops and reliable genotypic discrimination more than $80 \%$. The use of three crops is suitable for the selection to be accomplished with predictability of the real value of above $80 \%$ genotype.

Key words: improvement, variability, clonal selection, Vitis vinifera.

\section{INTRODUÇÃO}

Apesar da produção de uvas da espécie Vitis vinifera para elaboração de vinhos finos fazer parte da história do Brasil, a produção desses vinhos no país em nível comercial foi incentivada por acontecimentos que remetem ao final do século passado, nas décadas de 70 e 80. Portanto, o segmento dos vinhos finos (tranquilos e espumantes) encontra-se num processo de grandes transformações que, potencialmente, podem ser convertidas tanto em oportunidades quanto em ameaças. Nos últimos 20 anos, surgiram novos polos de produção em regiões de clima temperado de altitude; de clima temperado ou subtropical de relevo acidentado; de clima temperado ou subtropical com forte influência continental; de climas de transição entre tropical e subtropical; e de clima tropical, os quais demandam tecnologias específicas de cultivo.

IEmbrapa Uva e Vinho, 95700-000, Bento Gonçalves, RS, Brasil. E-mail: adeliano.cargnin@embrapa.br. Autor para correspondência. 
Nos últimos anos, houve avanços no cultivo de uvas finas para boa parte do território brasileiro, o aumento de empresas vinícolas e o incremento considerável de tipos e estilos de vinhos finos brasileiros, bem como ações de ordenamento territorial com a formação e organização de regiões demarcadas com status de Indicação Geográfica.

Nas castas tradicionais domesticadas e utilizadas na Europa para a produção de vinhos finos, foram feitas as primeiras seleções das melhores plantas (as mais produtivas, com maiores teores de açúcar e que preservassem as características do vinho desejado), caracterizando o processo de seleção clonal, até hoje utilizado em uvas para vinhos finos. Embora difícil conhecer as relações genéticas entre os clones, é importante entender que a variação entre os clones de uma mesma cultivar pode ser uma variação considerável e tal pode ser explorada para melhorar o rendimento e qualidade da videira. Pesquisas em vários países produtores têm demonstrado que o ambiente afeta o desempenho relativo dos diferentes clones de videira. Informações sobre a interação genótipo $\mathrm{x}$ ambiente são um recurso valioso para a seleção e recomendação do material mais adequado para plantio.

De acordo com LEÃO et al. (2003), a eficácia dos programas de melhoramento de uva de mesa depende principalmente da repetibilidade espacial e temporal dos caracteres sob seleção. Portanto, em todas as fases do programa de melhoramento, a avaliação segura da superioridade genotípica é fundamental e, consequentemente, a repetibilidade dos caracteres ao longo dos anos torna-se informação indispensável para o melhorista (RESENDE, 2002).

$O$ coeficiente de repetibilidade da característica possibilita estabelecer o número de observações fenotípicas que devem ser realizadas em cada indivíduo para que a discriminação, ou seleção, fenotípica entre genótipos seja eficiente, ou seja, consuma menos tempo e tenha menor custo de mão-deobra (CRUZ \& REGAZZI, 2001; DELLA BRUNA et al., 2012). Adicionalmente, a repetibilidade fornece o valor máximo que a herdabilidade no sentido amplo pode atingir, pois expressa a proporção da variância fenotípica, que é atribuída às diferenças genéticas confundidas com os efeitos permanentes que atuam na cultivar. Assim, esses parâmetros constituem instrumentos úteis para orientar os trabalhos de melhoramento (COSTA, 2003; NEGREIROS et al., 2008).

O presente trabalho teve por objetivo obter estimativas dos coeficientes de repetibilidade (r), determinação ou grau de previsibilidade $\left(\mathrm{R}^{2}\right)$ de características de clones de variedades de uvas viníferas e determinar o número de medições necessárias, capaz de proporcionar níveis de certeza (80, 90 e 95\%) da predição do valor real dos indivíduos para cada caráter.

\section{MATERIAL E MÉTODOS}

Este trabalho foi realizado a partir de dados médios das características: produção de fruto $\left(\right.$ kgplanta $\left.^{-1}\right)$, número de cachos ( cachos planta $\left.^{-1}\right)$, peso de cacho $(\mathrm{g})$, número de bagas (bagas cacho $\left.{ }^{-1}\right)$, peso de baga $(\mathrm{g}),{ }^{\circ}$ Brix, $\mathrm{pH}$ e acidez titulável $\left(\mathrm{gL}^{-1}\right)$, provenientes de dois experimentos sobre o comportamento de clones de duas variedades viníferas, publicados por WOLPERT et al. (1994) e WOLPERT et al. (1995).

$\mathrm{O}$ experimento do primeiro trabalho foi realizado por WOLPERT et al. (1994) e avaliou o desempenho agronômico de seis clones da variedade Chardonnay (Tabela 1). Os clones foram enxertados sobre o porta-enxerto AXR\#1 e plantados a campo em 1984, numa densidade de 1346 plantasha $^{-1}$, conduzidas em sistema de espaldeira, no Vale do Napa, Califórnia, Estados Unidos. As avaliações foram efetuadas anualmente, no período de 1989 a 1991.

O experimento do segundo trabalho foi realizado por WOLPERTet al. (1995) e avaliou o desempenho agronômico de sete clones da variedade Cabernet Sauvignon (Tabela 1). Os clones foram enxertados sobre o porta-enxerto Harmony e plantados a campo em 1984, numa densidade de 1397

Tabela 1 - Relação dos clones, ano e número de colheitas realizadas em dois experimentos.

\begin{tabular}{|c|c|c|c|}
\hline $\begin{array}{l}\text { Experimento/ } \\
\text { Variedade }\end{array}$ & Clone & Anosavaliados & $\begin{array}{c}\mathrm{N}^{\mathrm{o}} \text { de } \\
\text { colheitas }\end{array}$ \\
\hline \multirow{6}{*}{ Chardonnay } & FPMS 4 & 1989 a 1991 & 3 \\
\hline & FPMS 5 & 1989 a 1991 & 3 \\
\hline & FPMS 6 & 1989 a 1991 & 3 \\
\hline & FPMS 14 & 1989 a 1991 & 3 \\
\hline & FPMS 15 & 1989 a 1991 & 3 \\
\hline & FPMS 16 & 1989 a 1991 & 3 \\
\hline \multirow{7}{*}{ Cabernet Sauvignon } & FPMS 2 & 1990 e 1992 & 3 \\
\hline & FPMS 4 & 1990 e 1992 & 3 \\
\hline & FPMS 5 & 1990 e 1992 & 3 \\
\hline & FPMS 6 & 1990 e 1992 & 3 \\
\hline & FPMS 8 & 1990 e 1992 & 3 \\
\hline & FPMS 10 & 1990 e 1992 & 3 \\
\hline & FPMS 21 & 1990 e 1992 & 3 \\
\hline
\end{tabular}

FPMS = Foundation Plant Material Service, University of California. 
plantasha ${ }^{-1}$, conduzidas em sistema de espaldeira, no Norte do Vale de São Joaquim, Califórnia, Estados Unidos. As avaliações foram efetuadas anualmente no período de 1990 a 1992.

Com base nas médias de cada colheita dos dois experimentos, obtiveram-se as estimativas do coeficiente de repetibilidade $(\hat{\rho})$ e o coeficiente de determinação ou grau de previsibilidade $\left(\mathrm{R}^{2}\right)$ de todas as características avaliadas. $\mathrm{Na}$ estimação do coeficiente de repetibilidade, foi utilizado o método da análise de variância citado por CRUZ \& REGAZZI (2001), cujo procedimento está apresentado a seguir, de forma resumida.

O coeficiente de repetibilidade foi estimado por meio da correlação intraclasse, obtida da análise de variância, considerando o modelo estatístico reduzido, com base em médias de colheita e clones: $\mathrm{Y}_{\mathrm{ik}}=\mu+$ $\mathrm{g}_{\mathrm{i}}+\mathrm{c}_{\mathrm{k}}+{ }_{\mathrm{ik}}$; em que $\mathrm{Y}_{\mathrm{ik}}=$ valor médio observado, relativo ao i-ésimo clone, na k-ésima colheita; $\mathrm{m}=$ média geral; $\mathrm{g}_{\mathrm{i}}=$ efeito aleatório do i-ésimo clone sob influência do ambiente permanente $(i=1, \ldots, p$; $\mathrm{p}=$ clones $) ; \mathrm{c}_{\mathrm{k}}=$ efeito fixo do ambiente temporário na $\mathrm{k}$-ésima colheita $(\mathrm{k}=1, \ldots, \eta ; \eta=$ número de colheitas); $\mathrm{e}_{\mathrm{ik}}=$ erro experimental estabelecido pelos efeitos temporários do ambiente na k-ésima colheita, do i-ésimo clone. Nesse efeito, são incluídas, em uma única fonte, denotadas por resíduo, todas as demais fontes de variação não consideradas no modelo.

O coeficiente de repetibilidade r é obtido por: $r=\frac{\operatorname{Cô}\left(Y_{i k}, Y_{i k^{\prime}}\right)}{\sqrt{\hat{V}\left(Y_{i k}\right) \hat{V}\left(Y_{i k \prime}\right)}}=\frac{\hat{\sigma}_{g}^{2}}{\hat{\sigma}_{e}^{2}+\hat{\sigma}_{g}^{2}} ;$ em que $\hat{\sigma}_{g}^{2}=(\mathrm{QMG}-$

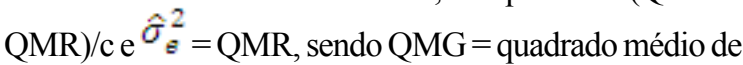
genótipos (clones), QMR = quadrado médio do resíduo.

Com base na média das $\eta$ colheitas (de cada experimento) e na estimação do coeficiente de repetibilidade obtido, foi calculado o coeficiente de determinação $\left(\mathrm{R}^{2}\right)$ por meio da seguinte expressão: $R^{2}=\frac{\eta r}{1+r(\eta-1)}$.

Por fim, foi estimado, para todas as características, o número mínimo de medições necessárias para predizer o valor real dos clones, com base em um coeficiente de determinação $\left(\mathrm{R}^{2}\right)$ preestabelecido $(0,80,0,90$ e 0,95), conforme CRUZ \& REGAZZI (2001), por meio da seguinte expressão: $\eta_{m}=\frac{R^{2}(1-r)}{\left(1-R^{2}\right) r}$; em que $\eta_{\mathrm{m}}=$ número de medições para predição do valor real; $\mathrm{R}^{2}=$ coeficiente de determinação; e $r$ = coeficiente de repetibilidade.

Todas as análises estatísticas foram realizadas com o uso do software GENES (2013).

\section{RESULTADOS E DISCUSSÃO}

Em ambos os experimentos, a existência de variabilidade genética foi detectada pelo teste $\mathrm{F}$, na maioria das características avaliadas (Tabela 2). Isso indica possibilidade de seleção e recomendação de clones promissores. Os experimentos demonstraram boa precisão experimental, com valores de coeficientes de variação (CV) dentro de um limite aceitável para esse tipo de experimento. As características avaliadas apresentaram CV menor de $12 \%$, com exceção de número de bagas/cacho na variedade Cabernet Sauvignon (Tabela 2).

As estimativas dos coeficientes de repetibilidade, obtidas pela informação de três colheitas realizadas nos clones das variedades Chardonnay e Cabernet Sauvignon, com o emprego do método da análise de variância, encontram-se na tabela 3. Em geral, os valores das estimativas foram consistentes e altas para as duas variedades. Observaram-se valores de menor magnitude para estimativas de repetibilidade (r) de algumas características, principalmente na variedade Cabernet Sauvignon. Esses efeitos podem ocorrer em razão de diversos fatores, como os próprios clones analisados nestes experimentos, o controle experimental, e variações ambientais como sazonalidade (FERREIRA et al., 2005). As estimativas desses experimentos influenciaram o decréscimo da estimativa média de repetibilidade e coeficiente de determinação, e o acréscimo do número de medidas necessárias. Os resultados evidenciam que,quando mais de um experimento é analisado, há mais confiabilidade, por demonstrar variações entre experimentos, revelando consistência e confiabilidade nas estimativas de repetibilidade, tornando um valor médio mais preciso. Valores altos de repetibilidade são desejáveis, pois, de acordo com CRUZ \& REGAZZI (2001), esperase que, ao escolher um genótipo, sua superioridade inicial perdure; e a veracidade desta expectativa é corroborada pelo coeficiente de repetibilidade, que, quanto mais alto, menor o número de medidas repetidas para predizer o valor real do indivíduo.

Os coeficientes de determinação, que demonstram a confiabilidade do valor fenotípico em predizer o valor real dos genótipos, apresentaram valores médios superiores a $80 \%$ quanto às oito características avaliadas nos clones das variedades Chardonnay e Cabernet Sauvignon. Esses valores de confiabilidade são referenciados (COSTA, 2003; LEÃO et al., 2003; NEGREIROS et al., 2008; DELLA BRUNA et al., 2012) como elevados, uma vez que, quando se seleciona um grupo de indivíduos, valores acima de $80 \%$ já podem ser considerados adequados. 
Tabela 2 - Análise de variância (modelo reduzido), média e coeficiente de variação (CV) de oito características avaliadas em clones de duas variedades viníferas.

\begin{tabular}{|c|c|c|c|c|c|}
\hline Característica & $\begin{array}{c}\text { QM } \\
\text { Colheita }\end{array}$ & $\begin{array}{c}\text { QM } \\
\text { Clone }\end{array}$ & $\begin{array}{c}\text { QM } \\
\text { Resíduo }\end{array}$ & Média & $\mathrm{CV}(\%)$ \\
\hline Produção de fruto & $14,75 * *$ & $19,26^{* *}$ & 1,35 & 9,03 & 12,84 \\
\hline Número de cachos & $2820,22 * *$ & $181,96^{* *}$ & 25,16 & 58,11 & 8,63 \\
\hline Peso de cacho & $7780,50 * *$ & $5230,27 * *$ & 409,17 & 162,33 & 12,46 \\
\hline Número de bagas & $1081,50 *$ & $4180,50 * *$ & 169,30 & 130,50 & 9,97 \\
\hline Peso de baga & $0,15^{* *}$ & $0,05^{* *}$ & 0,01 & 1,27 & 6,65 \\
\hline${ }^{\circ}$ Brix & $5,13 * *$ & $0,65^{\mathrm{ns}}$ & 0,62 & 22,67 & 3,48 \\
\hline $\mathrm{pH}$ & $0,01 * *$ & $0,02 * *$ & 0,001 & 3,33 & 0,65 \\
\hline Acidez titulável & $1,02 * *$ & $0,48 * *$ & 0,06 & 6,56 & 3,58 \\
\hline Produção de fruto & $2,18^{*}$ & $2,14^{*}$ & $\begin{array}{l}\text { ernet Sauv } \\
0,49\end{array}$ & 8,69 & 8,09 \\
\hline Número de cachos & $323,62 *$ & $22,16^{\mathrm{ns}}$ & 43,56 & 97,62 & 6,76 \\
\hline Peso de cacho & $779,44 * *$ & $340,89 * *$ & 39,24 & 89,53 & 6,99 \\
\hline Número de bagas & $36,33^{\mathrm{ns}}$ & $453,75^{\mathrm{ns}}$ & 402,39 & 84,90 & 23,63 \\
\hline Peso de baga & $0,18^{* *}$ & $0,01 * *$ & 0,001 & 1,00 & 3,01 \\
\hline${ }^{\circ}$ Brix & $3,38 * *$ & $0,71^{*}$ & 0,18 & 22,03 & 1,95 \\
\hline $\mathrm{pH}$ & $0,04 * *$ & $0,01 * *$ & 0,001 & 3,64 & 0,75 \\
\hline Acidez titulável & $0,85^{\mathrm{ns}}$ & $0,03^{\mathrm{ns}}$ & 1,33 & 6,26 & 5,83 \\
\hline
\end{tabular}

${ }^{\text {ns }}$ não significativo, $* *$ e $*$ significativo a 1 e $5 \%$ de probabilidade, respectivamente,pelo teste $\mathrm{F}$.

QM - quadrado médio.

As estimativas do número de medições necessárias para se obter valores de $80 \%, 90 \%$ e $95 \%$ de predição do valor real do indivíduo (ou coeficiente de determinação) para todas as características, encontram-se na tabela 4. Há variação considerável no número de colheita/medições necessárias para inferir com segurança a superioridade de um clone em relação a outro, conforme a característica a ser selecionada. Essa diferença também é percebida entre as variedades analisadas.
De forma geral, estabelecendo-se valor de $\mathrm{R}^{2}$ igual a 0,80 , pode-se predizer que são necessárias, em média, para as oito características avaliadas, de uma a três colheita/medições para inferir com segurança a superioridade de um clone em relação a outro. Entretanto, se for estabelecida necessidade de maior confiabilidade, expressa por $\mathrm{R}^{2}$ igual a 0,90 , seriam necessárias até sete colheitas/medições, ao passo que, ao estabelecer $\mathrm{R}^{2}$ igual a 0,95 , seriam necessárias 15 colheitas/medições, para praticar a seleção com

Tabela 3 - Estimativa dos coeficientes de repetibilidade (r) e coeficientes de determinação ( $\mathrm{R}^{2} \%$ ) de oito características de clones das variedades Chardonnay e Cabernet Sauvignon, obtidos pelo método da análise de variância.

\begin{tabular}{|c|c|c|c|c|c|}
\hline \multirow{2}{*}{ Característica } & \multicolumn{4}{|c|}{ 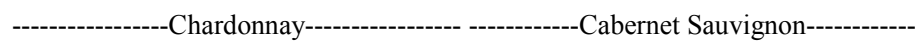 } & \multirow{2}{*}{$\mathrm{r}$ médio } \\
\hline & $\mathrm{r}$ & $\mathrm{R}^{2}$ & $\mathrm{r}$ & $\mathrm{R}^{2}$ & \\
\hline Produção de fruto $\left(\mathrm{kg} \mathrm{planta}^{-1}\right)$ & 0,81 & 93 & 0,53 & 77 & 0,67 \\
\hline Número de cachos (cachos planta ${ }^{-1}$ ) & 0,68 & 86 & 0,46 & 72 & 0,57 \\
\hline Peso de cacho $(\mathrm{g})$ & 0,80 & 92 & 0,72 & 88 & 0,76 \\
\hline Número de bagas (bagas cacho ${ }^{-1}$ ) & 0,89 & 96 & 0,90 & 96 & 0,89 \\
\hline Peso de baga $(\mathrm{g})$ & 0,65 & 85 & 0,78 & 92 & 0,72 \\
\hline${ }^{\circ}$ Brix & 0,82 & 93 & 0,49 & 74 & 0,66 \\
\hline $\mathrm{pH}$ & 0,94 & 98 & 0,77 & 91 & 0,86 \\
\hline Acidez titulável $\left(\mathrm{gL}^{-1}\right)$ & 0,72 & 89 & 0,82 & 93 & 0,77 \\
\hline
\end{tabular}


Tabela 4 - Número necessário de medições de oito características de clones das variedades Chardonnay e Cabernet Sauvignon, associados a diferentes graus de determinação do valor genotípico $\left(\mathrm{R}^{2}\right)$, a partir da repetibilidade estimada pelo método da análise de variância.

\begin{tabular}{|c|c|c|c|c|}
\hline $\mathrm{R}^{2}$ & Característica & Chardonnay & Cabernet Sauvignon & Média \\
\hline \multirow{8}{*}{0,80} & Produção de fruto $\left(\mathrm{kg} \mathrm{planta}^{-1}\right)$ & 1 & 3 & 2 \\
\hline & Número de cachos ( cachos planta $\left.^{-1}\right)$ & 2 & 4 & 3 \\
\hline & Peso de cacho $(\mathrm{g})$ & 1 & 1 & 1 \\
\hline & Número de bagas (bagas cacho-1) & 1 & 1 & 1 \\
\hline & Peso de baga $(\mathrm{g})$ & 2 & 1 & 1,5 \\
\hline & ${ }^{\circ}$ Brix & 1 & 4 & 2,5 \\
\hline & $\mathrm{pH}$ & 1 & 1 & 1 \\
\hline & Acidez titulável $\left(\mathrm{gL}^{-1}\right)$ & 2 & 1 & 1,5 \\
\hline \multirow{8}{*}{0,90} & Produção de fruto $\left(\mathrm{kg} \mathrm{planta}^{-1}\right)$ & 2 & 8 & 5 \\
\hline & Número de cachos (cachos planta $\left.{ }^{-1}\right)$ & 4 & 10 & 7 \\
\hline & Peso de cacho $(\mathrm{g})$ & 2 & 3 & 2,5 \\
\hline & Número de bagas (bagas cacho ${ }^{-1}$ ) & 1 & 1 & 1 \\
\hline & Peso de baga $(\mathrm{g})$ & 5 & 2 & 3,5 \\
\hline & ${ }^{\circ}$ Brix & 2 & 9 & 5,5 \\
\hline & $\mathrm{pH}$ & 1 & 3 & 2 \\
\hline & Acidez titulável $\left(\mathrm{gL}^{-1}\right)$ & 3 & 2 & 2,5 \\
\hline \multirow{8}{*}{0,95} & Produção de fruto $\left(\mathrm{kg} \mathrm{planta}^{-1}\right)$ & 4 & 16 & 10 \\
\hline & Número de cachos (cachos planta ${ }^{-1}$ ) & 9 & 22 & 15,5 \\
\hline & Peso de cacho $(\mathrm{g})$ & 5 & 7 & 6 \\
\hline & Número de bagas (bagas cacho-1) & 2 & 2 & 2 \\
\hline & Peso de baga $(\mathrm{g})$ & 10 & 5 & 7,5 \\
\hline & ${ }^{\circ}$ Brix & 4 & 19 & 11,5 \\
\hline & $\mathrm{pH}$ & 2 & 6 & 4 \\
\hline & Acidez titulável $\left(\mathrm{gL}^{-1}\right)$ & 7 & 4 & 5,5 \\
\hline
\end{tabular}

a confiabilidade desejada. Contudo, esses números de colheitas/medições elevados, necessários para praticar a seleção com a confiabilidade desejada, com $\mathrm{R}^{2}$ de 0,90 e 0,95 , são para uma ou outra característica avaliada. Por outro lado, há características que permitem ser selecionadas com apenas uma a duas colheitas. Isso, possivelmente, se deve ao fato de diferenças de herdabilidade para cada característica. Enfim, para a maioria das características avaliadas na média das duas variedades, considerando $\mathrm{R}^{2}$ de 0,90 , seriam necessárias de três a cinco colheitas/medições e, para $\mathrm{R}^{2}$ de 0,95 , de cinco a sete colheitas/medições para praticar a seleção com a confiabilidade desejada.

Em programas de melhoramento de viníferas com base na seleção clonal, quanto às oito características avaliadas, pode-se dizer que três medições possibilitariam discriminação dos clones com $80 \%$ de probabilidade de se estar fundamentado no valor real de cada um deles. Tal nível de confiabilidade tem sido considerado adequado em esquemas seletivos (RESENDE, 2002).
Portanto, recomenda-se que, em programa de melhoramento genético de viníferas com base em seleção clonal sejam realizados, no mínimo, três colheitas/medições na fase final de avaliação dos clones promissores. A aplicação do menor número de medições é desejável, em termos de economia de tempo e mão-de-obra. Assim, a utilização de um número maior de colheitas não é vantajosa, tendo em vista aspectos práticos e econômicos. Três medições parecem ser adequadas tanto para aplicação técnica e prática quanto para que o sucesso de um programa de melhoramento genético não seja comprometido.

\section{CONCLUSÃO}

As estimativas dos coeficientes de repetibilidade obtidas para as duas variedades apresentam valores de magnitude muito semelhantes. As estimativas de repetibilidade média geral, nas oito características, são superiores a 0,60 , demonstrando regularidade do desempenho dos clones nas várias medições (colheitas) e confiabilidade na

Ciência Rural, v.46, n.2, fev, 2016. 
discriminação genotípica superior a $80 \%$. O emprego de três colheitas (medições) é adequado para que a seleção em programa de melhoramento possa ser praticada com previsibilidade do valor real do genótipo acima de $80 \%$.

\section{REFERÊNCIAS}

COSTA, J.G. Estimativas de repetibilidade de alguns caracteres de produção em mangueira. Ciência Rural, v.33, n.2, p.263266, 2003. Disponível em: <http://dx.doi.org/10.1590/S0103$84782003000200013>$. Acesso em: 21 jul. 2014. doi: 10.1590/ S0103-84782003000200013.

CRUZ, C.D.; REGAZZI, A.J. Modelos biométricos aplicados ao melhoramento genético. 2.ed. rev. Viçosa, MG: UFV, 2001. 390p.

DELLA BRUNA, E. et al. Uso do coeficiente de repetibilidade na seleção de clones de pessegueiro para o litoral sul de Santa Catarina. Revista Brasileira de Fruticultura, v.34, n.1, p.206215, 2012. Disponível em: <http://dx.doi.org/10.1590/S010029452012000100028>. Acesso em: 21 jul. 2014. doi: 10.1590/ S0100-29452012000100028.

FERREIRA, A. et al. Repetibilidade e número de colheitas para seleção de clones de cana-de-açúcar. Pesquisa Agropecuária Brasileira, v.40, n.8, p.761-767, 2005. Disponível em: <http:// www.scielo.br/scielo.php? script $=$ sci_issuetoc $\&$ pid $=0100$ -
204X20050008\&lng=pt\&nrm=iso $>$. Acesso em: 21 jul. 2014. doi: $10.1590 / \mathrm{S} 0100-204 \mathrm{X} 2005000800005$.

GENES - a software package for analysis in experimental statistics and quantitative genetics. Acta Scientiarum, v.35, n.3, p.271-276, 2013. Disponível em: <http://dx.doi.org/10.4025/actasciagron. v35i3.21251>. Acesso em: 25 jul. 2014. doi: 10.4025/actasciagron. v35i3.21251.

LEÃO, P.C.S.; COSTA, J.G. Estimates of repeatability and path coeficients on grapes. Crop Breeding and Applied Biotechnology, v.3, n.3, p.231-236, 2003.

NEGREIROS, J.R.S. et al. Estimativas de repetibilidade de caracteres de produção em laranjeiras-doces no Acre. Pesquisa Agropecuária Brasileira, v.43, n.12, p.1763-1768, 2008. Disponível em: <http://dx.doi.org/10.1590/S0100204X2008001200017>. Acesso em: 21 jul. 2014. doi: 10.1590/ S0100-204X2008001200017.

RESENDE, M.D.V. de. Genética biométrica e estatística no melhoramento de plantas perenes. Brasília: Embrapa Informação Tecnológica, 2002. 975p.

WOLPERT, J.A.et al. Filed performance of six Chardonnay clones in the Napa Valley. American Journal of Enology and Viticulture, v.45, n.4, p. 393-400, 1994

WOLPERT, J.A. et al.Viticultural performance of seven Cabernet Sauvignon clones in the northern San Joaquin Valley, California.American Journal of Enology and Viticulture, v.46, n.4, p.437-441, 1995. 